\title{
FORMAÇÃO CONTINUADA DE PROFESSORES E PROFESSORAS: O PDE/PR ${ }^{1}$
}

\author{
Denise Rosana da Silva Moraes ${ }^{2}$ \\ Universidade Estadual do Oeste do Paraná - Unioeste \\ Iara de Oliveira Gomes ${ }^{3}$ \\ Teresa Kazuko Teruya ${ }^{4}$ \\ Universidade Estadual de Maringá- UEM
}

\section{RESUMO}

O Programa de Desenvolvimento Educacional - PDE/PR foi lançado no ano de 2007. Trata-se de uma política educacional de formação continuada de professores/as da rede pública de educação do Estado. O objetivo deste artigo é compreender as diretrizes e encaminhamentos do PDE/PR. O referencial teórico metodológico baseia-se nos estudos da pedagogia crítica, para analisar os documentos oficiais disponibilizados no site www.diadiaeducacao.pr.gov.br. Como resultado dessa formação orientada pelos/as docentes universitários, os/as professores/as PDE estão produzindo material didáticopedagógico e artigos científicos, que são disponibilizados on line. Concluímos que se trata de uma proposta inovadora, apesar de incipiente para uma avaliação, e ainda não encontramos modelos públicos similares.

Palavras-chave: Educação. Formação de professores. Programa de Desenvolvimento Educacional. Prática docente.

\section{CONTINUOUS FORMATION OF TEACHERS AND TEACHERS: THE PDE OF PARANÁ.}

\begin{abstract}
The Educational Development Program - PDE/PR, was launched in 2007. This is an educational policy for continuous training of teachers and teachers of public education of state. The aim of this paper is to understand the guidelines and directives of the PDE/PR. The theoretical reference of this research is based on studies of critical educacion and others to analyze the official documents available at the site www.diadiaeducacao.pr.gov.br. As a result of targeted training by the teachers, college students, the teachers, the PDE are producing teaching materials, pedagogical and scientific articles available on line. We conclude that this is an innovative proposal and we have not found similar public models.

Keywords: Education. Teacher education. Educational Development Program. Teaching practice.
\end{abstract}

\section{Introdução}

O surgimento das escolas públicas e a formação de professores e professoras para o cumprimento do exercício profissional estão intrinsecamente relacionados à institucionalização da instrução pública idealizada no final do século XVIII. Aos poucos a 
educação deixou de ser uma das funções restritas às famílias abastadas e passou a ser assunto de pauta das políticas sociais, desde a implementação e ampliação do ensino primário a todas as camadas da população fundada na doutrina liberal.

A exigência social da escola e de profissionais adequadamente preparados para desempenhar as funções pedagógicas especificas, em nenhum momento, foi tão evidenciada. No entanto, um professor nunca define sozinho o seu próprio saber profissional. Ao contrário, esse saber é produzido socialmente, como resultado de uma negociação entre diversos grupos, o que significa dizer que não existe profissão e conhecimento sem reconhecimento social, como nos mostra a história da pedagogia e da educação, a maneira de os professores ensinarem é estabelecida com o tempo e com as mudanças sociais [...] (NEGRÃO, 2008, p. 178).

A formação de professores e professoras para atuar na educação formal, seja ela inicial ou continuada, "pouco a pouco se constitui em uma área de investigação, que se propõe a oferecer soluções e problematizar o sistema educacional brasileiro". (NEGRÃO, 2008, p. 178) O mundo globalizado criou novas exigências para a formação docente. Atualmente o discurso corrente valoriza a necessidade de formação dos/as educadores/as para atuar no campo disciplinar inter-relacionado com outras áreas do conhecimento e contextualizada no tempo e espaço.

O presente trabalho trata do programa de formação continuada de professores e professoras da Educação Básica em desenvolvimento nas escolas públicas no Estado do Paraná, denominado Programa de Desenvolvimento Educacional - o PDE/PR ${ }^{5}$. A preocupação com a formação tem ocupado a agenda dos discursos políticos, entretanto as práticas de materialização dessas propostas, na maioria das vezes, não se consolidam como uma política educacional que se estabelece como um direito e um fato.

O Plano de Desenvolvimento da Educação - PDE nacional foi lançado pelo Ministério da Educação - MEC em 24 de abril de 2007, com uma recepção favorável e atenta da opinião pública, pois foi amplamente divulgado. $\mathrm{O}$ aspecto que mais chamou a atenção em relação ao Plano do Governo Federal foi sobre a qualidade do ensino da Educação Básica e a formação dos docentes que atuam nesta modalidade de ensino. Um plano ao demonstrar em seu teor preocupação com a qualidade do ensino de um país, ganha legitimidade, porque se espera uma preocupação legitima da parte de seus dirigentes.

Saviani (2009) empreende uma análise do PDE nacional que vai além das primeiras impressões, discute a lógica que se encontra na base da formulação do plano quanto das expectativas favoráveis que alimentam a grande aprovação quando o mesmo foi anunciado. Segundo o autor, o PDE nacional aparece como um projeto guarda-chuva que abrigaria a maioria dos programas em desenvolvimento pelo MEC. A partir do lançamento do Programa de Aceleração do Crescimento - PAC, lançado em 28 de janeiro de 2007 pelo Governo Federal, cada um dos ministérios teria que indicar ações para se enquadrarem no referido programa. Neste intuito, o MEC lança o Índice de Desenvolvimento da Educação Básica - IDEB, para atrelar diversas ações e os devidos ajustes, que já se encontravam na pauta do Ministério. Essas ações teriam como obrigatoriedade abranger todos os níveis e modalidades de ensino, além ainda de medidas de apoio e de infraestrutura.

Entre as ações que incidiam sobre a Educação Básica, situam-se o Fundo de Manutenção e Desenvolvimento da Educação Básica e de Valorização dos Profissionais da 
Educação - Fundeb e o Plano de metas do PDE nacional - IDEB. São duas ações relacionadas ao piso do magistério e a formação de professores/as.

O Programa de Desenvolvimento Educacional - PDE/PR, objeto desse trabalho, tem relação com a política maior do Governo Federal, contudo, existe uma distinção entre as duas propostas. A Secretaria de Estado da Educação - SEED do Paraná com a Secretaria de Estado da Ciência e Tecnologia e Ensino Superior instituem o PDE/PR como uma política educacional de formação continuada dos professores e professoras da rede pública estadual. O programa propõe um conjunto de ações organicamente articuladas, que foram delineadas a partir da necessidade da Educação Básica, e buscou no Ensino Superior a contribuição teórica e prática para melhorar a qualidade da Educação Pública paranaense.

Nesse artigo realizamos uma investigação acerca da proposta de formação continuada de professores/as da Educação Básica do PDE/PR. Nosso objetivo é compreender as diretrizes e encaminhamentos, analisando documentos oficiais que se apresentam como uma nova concepção de formação continuada que integra a política de valorização de professores/as atuantes na Rede Pública Estadual de Ensino do Estado do Paraná. A justificativa para implantação desse Programa é a idealização e materialização de uma capacitação de professores/as, em que os/as mesmos/as sejam produtores/as de conhecimento no processo de ensino e aprendizagem.

$\mathrm{Na}$ análise documental articulamos uma interlocução com autores críticos que em suas investigações defendem a boa formação de professores, para além de estratégias governamentais, como uma política de nação. Entendemos que essas políticas públicas educacionais estão inseridas em um cenário amplo de transformações econômicas, políticas e geopolíticas que caracterizam o mundo contemporâneo. As diretrizes organizacionais e curriculares são portadoras de intencionalidades, idéias, valores e atitudes que influenciam as escolas e seus profissionais na configuração das práticas pedagógicas, determinando um tipo de sujeito a ser formado. Entretanto, os profissionais da educação podem aderir ou resistir a essas políticas e diretrizes, ou ainda dialogar com elas, para formular e realizar coletivamente práticas pedagógicas em razão de outro tipo de sujeito a ser educado.

Em seguida, apresentaremos o Programa de Desenvolvimento Educacional do Estado do Paraná - PDE/PR para refletir criticamente sobre a sua elaboração, configuração, materialização e abrangência. E por fim, defendemos uma formação continuada que extrapole as estratégias imediatistas, e se configure como uma política de Estado, devidamente articulada às Universidades públicas.

\section{O Programa de Desenvolvimento Educacional do Estado do Paraná - PDE/PR}

$\mathrm{O}$ PDE/PR se configura como um programa de formação continuada atento às reais necessidades de enfrentamento de problemas ainda presentes na Educação Básica, buscando superar o modelo de formação continuada concebido de forma homogênea e descontínua. Trata-se de um programa integrado às instituições de ensino superior e ainda, de segundo as diretrizes norteadoras, com possibilidades de criação de condições efetivas, no interior da escola, para debate e promoção de espaços para a construção coletiva do saber.

O referido programa foi idealizado durante a elaboração do Plano de Carreira do Magistério (Lei Complementar n. 103, de 15 de março de 2004). Foi aprovado o plano de carreira do Magistério Público do Estado do Paraná logo após reuniões conjuntas entre gestores da Secretaria de Estado da Educação - SEED e representantes do Sindicato dos 
professores - APP - Sindicato dos Trabalhadores em Educação Pública do Paraná. Neste programa, o governo do Estado do Paraná tinha a incumbência de cumprir a legislação maior, a LDB 9394/96, que em seu teor garante a necessidade de um programa formativo em serviço para os trabalhadores da Educação. A partir de 1996 quando a LDB é promulgada, em relação à formação de professores/as é conferido particular relevo, sendo, portanto, direito de todos/as os/as professores/as, ampla participação em serviço a programas de formação continuada.

A proposta de valorização da carreira docente em comum acordo com a APPSindicato foi discutida amplamente nas instâncias governamentais e na APP-Sindicato, as quais buscavam um formato adequado que correspondesse ao consenso entre as partes. Entre 2005 e 2006 foi aprovada a proposta do PDE/PR, um programa de formação continuada de professores/as da rede pública de Educação Básica do Paraná, que materializa o plano de cargos e salários dos trabalhadores em educação do Estado. No ano de 2006, a Secretaria de Estado da Educação - SEED/PR aprovou o programa para ascensão na carreira do magistério, com o discurso de promover melhorias na qualidade de educação do Estado. Com a concordância dos representantes dos/as professores/as e dos gestores da SEED, o PDE/PR iniciou suas atividades a partir de 2007, com o objetivo de concretizar as ações estabelecidas nas diretrizes do programa paranaense. O governo do Estado do Paraná faz um convite às universidades estaduais e federais do Estado para articuladas à Secretaria de Estado da Educação SEED/PR assumirem esse projeto de formação de professores/as. Este diálogo com as universidades aconteceu em vários momentos, e a partir destes, foi reformulado o plano de formação, que inicialmente não previa avanço para os/as professores/as já titulados, mestres e doutores, o que para as Instituições de Ensino Superior - IES significa a deslegitimação de seus próprios programas de formação em nível strictu sensu.

Participar desse programa institucional de formação que articulou as IES e as escolas de educação básica é uma possibilidade de se consolidar uma formação continuada ao longo da vida profissional, no entanto, a preocupação das instâncias formadoras é sobre a necessidade da garantia de que possa vir a se constituir como política de Estado.

O Professor PDE (nome dado ao professor inserido no PDE/PR) tem afastamento integral no primeiro ano para se dedicar aos estudos e pesquisas, devendo frequentar assiduamente os cursos e eventos oferecidos pela universidade. No segundo ano, este/a professor/a retorna à escola de origem para cumprir uma carga horária de $75 \%$, ficando 25\% para implementar seu plano de ação elaborado a partir da pesquisa desenvolvida junto ao Professor Orientador das IES. Ao optar pela implementação do PDE/PR, o Paraná corrobora o PDE nacional, apesar de inovar, pois estabelece uma interlocução junto às universidades públicas do Estado. Na formação presencial, há um tempo para estudo e contato direto com docentes que se dispõem a colaborar com a formação continuada. Diferente do PDE nacional que prevê a formação continuada à distância organizada pela Universidade Aberta do Brasil - UAB. Dessa forma, há uma tendência em deslegitimar as IES públicas e os cursos presenciais para a formação de professores e professoras no país.

De acordo com Dourado (2008) o Governo Federal vem implementando ações em busca de maior organicidade entre os diversos setores que compõem a estrutura do Ministério. Tendo o PDE nacional como norte das atuais ações institucionais, o MEC sinaliza claramente para um redimensionamento de sua atuação, ao destacar a formação de professores. Para o autor, o projeto da Universidade Aberta do Brasil (UAB) engendrado em 2005 pelo MEC, passa a ser espaço de atuação da recém criada Diretoria de Educação a Distância. A UAB tem como competência prioritária a formação e capacitação inicial e 
continuada de professores para a Educação Básica, com a utilização de metodologias da educação à distância. $\mathrm{O}$ autor problematiza esse cenário expansionista da educação superior e da formação de professores em especial e, nos remete a análises mais amplas das políticas do setor, sem prejuízo de identificar os limites e possibilidades de processos de formação de qualidade, sejam em cursos presenciais ou em cursos à distância.

A preocupação se refere à quantidade de oferta que instituições privadas e públicas de ensino superior à distância, com o aval do governo brasileiro que considera tal política educacional uma importante alternativa para viabilizar a formação universitária de $30 \%$ dos estudantes brasileiros até 2011.

Quanto à qualidade, Dourado (2008), assevera que, tal procedimento educativo a distância muitas vezes nem sequer menciona a palavra projeto pedagógico, notando ainda o recrudescimento de pesquisas sobre os elementos que vão se tornando mais presentes nos debates do cenário educacional, tais como: os papéis dos professores e tutores nos processos de ensino e aprendizagem.

As políticas de formação precisam romper com a dicotomia entre ensino presencial e ensino à distância que, no caso brasileiro, tem contribuído para posições extremas de "fetichização" ora do ensino presencial ora do ensino à distância (DOURADO, 2008, p. 910). Para ele, isso pressupõe a necessidade de garantia de um projeto político-pedagógico que garanta uma sólida formação teórico-prática, professores/as com formação strictu sensu, condições adequadas de oferta, de laboratórios e bibliotecas, material didáticopedagógico em cursos presenciais e a distância, ressaltado por ele, que estes últimos devem garantir, ainda e não somente, estrutura adequada de acompanhamento por meio de encontros presenciais regulares, além de outros meios envolvendo as tecnologias de informação e comunicação (TIC).

Com as inovações tecnológicas na educação, os recursos eletrônicos trazem consigo a promessa de contribuir decisivamente para arrefecer o cansaço humano. Entretanto, contraditoriamente, gera preocupação pela perspectiva atual da modalidade de formação. Entendemos que, para se chegar ao patamar de países que já estabeleceram e alcançaram suas metas de uma educação de qualidade, a formação de professores/as no Brasil precisa ser encarada como uma política instituída que tem inicio e não tem fim, para além dos ditames de mercado. É fundamental que a formação presencial não seja sucumbida pela formação à distância, já que as IES são o lócus dessa formação.

A estrutura básica da UAB e dos Consórcios deve se assemelhar mais a uma fábrica, enfatizando a alta produção de cursos (planejamento curricular e pedagógico; preparação de roteiros de cursos; produção audiovisual; de textos de acompanhamento; atendimento a suporte ao aluno; avaliação do aluno e do curso), via várias formas tecnológica (BARRETO, 2008, p. 929).

O problema da institucionalidade das $\mathrm{UAB}$, segundo a autora, é a re-instauração oficial da dualidade educacional. Na medida em que é configurada uma política nacional de formação de professores à distância, apartada da presencial, não apenas modalidades de ensino são postas em jogo, mas é promovida segundo ela uma cisão radical. O destaque para Barreto é a constituição do sistema paralelo supostamente mais democrático e, sem dúvida, mais defensável como viabilidade econômica. Ou seja, o que está em questão é o barateamento desta formação, nos seus diferentes sentidos. 
Em síntese, para Barreto (2008) a política nacional de formação de professores à distância até pode sugerir movimentos de aproximação centrados na sua fragilidade. Entretanto, as condições da sua produção e o escopo assumido apontam para o sentido oposto, trazendo para o centro da discussão as implicações deste projeto que, a um só tempo, ampliando e reduzindo a contextualização das TIC no país, leva ao limite a substituição tecnológica e atinge a institucional.

Contrariando essa lógica, ao conclamar as universidades públicas paranaenses para participar efetivamente de todo o processo de formação dos professores da Educação Básica, o governo estadual estará de fato corroborando a modalidade de formação presencial? Será que a Secretaria de Estado da Educação legitimada pelo governo estadual estará se contrapondo aos ditames do mercado, que tem ofertado uma formação fragmentada e aligeirada de professores/as, pautando a organização pedagógica no aprender a aprender? Como todo processo de formação ainda incipiente, a busca dessas respostas exige a participação crítica das IES do Estado, desde a concepção do programa, seu desenvolvimento e sua avaliação crítica. $O$ trabalho docente prevê uma organização do debate crítico, para estimular a curiosidade, problematizar o conteúdo e confrontar as idéias e opiniões que caracterizam a cultura dominante de valores, modismos e ideologias que circulam nos meios de comunicação. Por isso, "a tarefa do professor como mediador é fundamental no processo de transformação do individuo através da linguagem capaz de favorecer a incorporação de um novo saber" (TERUYA, 2006, p.76).

A autora investiga os efeitos dos conteúdos midiáticos nas consciências individuais argumentando que as transformações sociais decorrentes dos avanços tecnológicos continuam submetidas à lógica do capital e, por isso, merecem uma reflexão crítica em favor da consciência coletiva. As inovações tecnológicas, altamente sofisticadas, embora favoreça grandes benefícios as pessoas não têm atendido às populações que sobrevivem em condições precárias de absoluta miséria. Pensando nisso, Teruya (2006, p.11) diz que: "só é possível projetar um mundo melhor se a ciência e a tecnologia forem democratizadas por meio de políticas educacionais que garantam o acesso ao saber nas escolas públicas". Para possibilitar uma melhoria da qualidade de vida, portanto, é preciso combater o ensino aligeirado para os trabalhadores e lutar por uma formação profissional consistente e consciente dos benefícios sociais da democratização do conhecimento técnico e científico. As tecnologias embutidas no computador estão em constante processo de inovação e oferecem uma variedade de tarefas e permitem o acesso imediato às informações. Com os avanços da tecnologia online, é possível vislumbrar a formação continuada à distância de alunos/as e professores/as conectados à internet com qualidade.

A partir da adoção pelo Estado de políticas de cunho neoliberais na década de noventa com repercussão até a contemporaneidade, os professores foram sendo formados para uma atuação acrítica, onde as práticas descontextualizadas de formação tem se pautado no mero cumprimento de tarefas, numa espécie de receituário didático. $\mathrm{O}$ cotidiano da escola é extremamente dinâmico, se não houver condições de uma boa formação em serviço, de tempo e espaço para um estudo denso, de uma compreensão dos fundamentos teóricos que norteiam tais concepções e do entendimento de que escola se está falando, qual o perfil do/da profissional que se está formando, é muito difícil encontrar formas de resistência para garantir que a escola pública seja de direito e de fato democrática.

A Lei de Diretrizes e Bases da Educação Nacional, 9394/96, em relação aos profissionais da educação no texto do art. 67, recomenda alguns princípios importantes que devem nortear a formação dos profissionais da educação, tais como: "I) a associação entre 
teorias e práticas, inclusive mediante a capacitação em serviço" Prevê ainda que: "Os sistemas de ensino promoverão a valorização dos profissionais da educação, assegurandolhes [...] período reservado a estudos, planejamento e avaliação, incluído na carga de trabalho" (BRASIL, 1996).

A legislação, apesar de sua discutida flexibilidade, aponta significativos avanços ao contemplar a formação de professores/as em serviço para associar as teorias com as práticas sociais. Essa é uma recomendação relevante para contribuir com a superação da dicotomia entre teoria e prática, ainda existente na formação continuada dos professores da Educação Básica. A universalização da Educação Básica contemplada na LDB é uma realidade que requer a formação de um contingente considerável de professores/as para atender a demanda dessa modalidade de Ensino. A maioria absoluta desses estudantes está matriculada em escolas públicas brasileiras. Esse espaço escolar é também o único meio para apropriação do conhecimento sistematizado e historicamente produzido.

Os estudos sobre formação de professores da Associação Nacional de PósGraduação e Pesquisa em Educação (ANPED) têm apontado que uma grande parcela dos programas de formação continuada dos professores no Brasil caracteriza-se como ações isoladas. Ocorre o predomínio da descontinuidade e fragmentação e, muitas vezes, desvinculadas das práticas docentes.

A formação de professores/as tem sido pautada na demanda do mercado, com base na reestruturação produtiva, na expressão de Saviani (2009), é uma espécie de "pedagogia dos resultados". O governo equipa-se com os instrumentos de avaliação dos produtos, forçando um processo que se ajuste às exigências postas pelas demandas das empresas.

É, pois, uma lógica de mercado que se guia nas atuais circunstâncias, pelos mecanismos das chamadas 'pedagogia das competências' e da 'qualidade total'. Esta, assim como nas empresas, visa obter a satisfação total dos clientes e interpreta que, nas escolas, aqueles que ensinam são prestadores de serviço; os que aprendem são clientes; e a educação é um produto que pode ser produzido com qualidade variável. Sob a égide da qualidade total, o verdadeiro cliente das escolas é a empresa ou a sociedade, e os alunos são produtos que os estabelecimentos de ensino fornecem a seus clientes (SAVIANI, 2009, p.45).

Nesta esteira de proposições o encaminhamento das práticas de formação de professores tem resultado num emaranhado de tarefas, alijadas de uma discussão crítica, de um envolvimento dos pares como mentores de sua própria formação, aliados as IES.

Para Saviani (2009), ao prover de recursos para a Educação brasileira, o governo estaria de fato, colaborando com a qualidade necessária para elevar a educação a um patamar civilizado, condizente com a magnitude de seu território, de sua população e de sua economia. Além disso, poderia equipar adequadamente às escolas e dotá-las de professores com formação obtida em cursos de longa duração, com salários gratificantes, compatíveis com seu alto valor social. Isto, segundo o autor, permitiria transformar as escolas, nas quais as crianças nelas permaneceriam em tempo integral, portanto, não teriam como fracassar; teriam menos dificuldades para aprender.

O êxito das crianças estaria vinculado ao resultado de um trabalho pedagógico desenvolvido densamente, próprio de profissionais bem preparados e que acreditam na importância do seu papel em relação à sociedade, sendo remunerados à altura de sua importância social.

A legislação vigente o programa PDE/PR assume os seguintes pressupostos: 
a) reconhecimento dos professores/as como produtores de conhecimento sobre o processo de ensino e de aprendizagem

b) organização de um programa de formação continuada atento às reais necessidades de enfrentamento de problemas ainda presentes na Educação Básica;

c) superação do modelo de formação continuada concebido de forma homogênea e descontínua;

d) organização de um programa de formação continuada integrado com as instituições de ensino superior;

e) criação de condições efetivas, no interior da escola, para o debate e promoção de espaços para a construção coletiva do saber.

O programa proporciona aos professores/as o retorno às atividades acadêmicas junto às Instituições de Ensino Superior públicas do Estado na modalidade presencial e semipresencial. Quando os/as professores/as PDE entram em contato com seus pares nas escolas por meio de atividades online, postadas na página do Portal Dia a dia Educação disponibilizada pela Secretaria de Estado da Educação têm a oportunidade de realizar atividades colaborativas nesse ambiente. Essa formação entre os pares denomina-se formação continuada em rede.

Nesse sistema online, os/as professores/as PDE inserem e discutem com outros colegas, os textos acadêmicos e as experiências docentes com o objetivo de instituir uma dinâmica permanente de reflexão, utilizando o aparato tecnológico disponibilizado pelo Estado. Essa experiência com o uso de computadores conectados à Internet propicia a aproximação dos/as professores/as PDE com os colegas nas escolas. Ainda há professores e professoras com dificuldades em lidar com essas tecnologias online. Não houve um trabalho anterior de formação para o uso das novas tecnologias que são exigidas quando da participação no programa.

Essa inter-relação entre a escola básica e a universidade possibilita o redimensionamento das práticas docentes, as reflexões pertinentes sobre a organização do trabalho pedagógico, a natureza e especificidade da escola, o currículo, a gestão escolar, o projeto político-pedagógico e a avaliação, entre outras discussões relevantes. Essa proposta de formação visa o fortalecimento da articulação entre os dois níveis educacionais, a Educação Básica e o Ensino Superior.

O grande problema encontrado nos programas organizados para atender a demanda de formação de educadores/as no Brasil e no Estado do Paraná tem sido a oferta de cursos aligeirados, uma vez que a progressão da carreira é garantida com o acúmulo de certificações de cursos estanques e aleatórios. As políticas educacionais até então e as ações para a formação profissional tem estado distantes de uma reflexão crítica sobre sua área de atuação e derivadas de práticas isoladas.

O PDE/PR Paraná parece significar um avanço para formação de professores/as já que, proporciona o retorno dos/as mesmos/as às atividades acadêmicas para elaborar um plano de trabalho com orientação de um/uma professor/a orientador/a de uma universidade. No primeiro momento, esse plano de trabalho é uma proposta de intervenção na sua realidade escolar e está estruturada em três eixos, a saber: a proposta de estudo, a elaboração de material didático e a coordenação de Grupo de Trabalho em Rede, este desenvolvido na modalidade semipresencial com seus pares nas escolas da rede estadual.

Para a implementação desse modelo de formação, a Secretaria de Estado da Educação assegurou aos professores/as PDE a infraestrutura, as ferramentas tecnológicas e 
o afastamento remunerado de suas atividades regulares para propiciar o bom aproveitamento e desenvolvimento da formação docente.

Os fundamentos explicitados do Programa de formação da Secretaria de Estado da Educação baseam-se nos seguintes eixos norteadores:

- compromisso com a diminuição das desigualdades sociais;

- articulação das propostas educacionais com o desenvolvimento econômico, social, político e cultural da sociedade;

- defesa da educação básica e da escola pública, gratuita de qualidade, como direito fundamental do cidadão;

- articulação de todos os níveis e modalidades de ensino;

- compreensão dos profissionais da educação como sujeitos epistêmicos;

- estímulo ao acesso, à permanência e ao sucesso de todos os alunos na escola;

- valorização do professor e dos demais profissionais da educação;

- promoção do trabalho coletivo e da gestão democrática em todos os níveis institucionais;

- atendimento e respeito à diversidade cultural.

De acordo com os documentos oficiais, as diretrizes adotadas enfatizam a relação entre os conteúdos de referência e os saberes escolares das disciplinas que compõem a matriz curricular. A proposta pedagógica segue uma concepção teórico-metodológica diferente da pedagogia das competências e dos PCN, cujos fundamentos apóiam-se nos quatro pilares da educação propostos pela UNESCO: aprender a aprender; aprender a ser; a viver com; e aprender a fazer.

A decisão de não utilizar os fundamentos dos PCN para a elaboração dos parâmetros dessa modalidade de formação, corrobora a leitura das Instituições de Ensino Superior (IES), que questionam e refutam o ideário da pedagogia das competências. A proposta tem como pano de fundo a promoção da leitura, da escrita, da interpretação e da inserção crítica do jovem no mundo do trabalho. São os grandes objetivos que determinam à existência da Educação Básica no Estado. Nesse sentido, concordamos com Rodrigues quando a respeito do/a educador/a necessário:

Em primeiro lugar, ele deve estar comprometido politicamente com a sua tarefa de educador. Esse comprometimento exige que as pessoas tenham consciência da responsabilidade que lhes foi confiada. Do educador se exige uma constante ocupação com o ato educativo. Exige-se um crescimento dessa consciência política, que se obtém no próprio processo político do trabalho. Essa consciência política não se obtém através de uma verificação da tendência psicológica de alguém ou de um teste psicológico para avaliar a vocação. À medida que o educador, enquanto educador compreende a importância social do seu trabalho, a dimensão transformadora da sua ação, a importância social, cultural, coletiva e política da sua tarefa, o seu compromisso cresce (RODRIGUES, 2000, p.65-66).

A necessidade de engajamento o/a professor/a ao participar de um programa de formação é a exigência da apreensão critica da natureza dessa proposta, para que possa contribuir em sua formulação/ou reformulação, onde a experiência docente precisa ser 
levada em conta. Uma das finalidades de todo programa de formação de educadores/as é de contribuir com a preparação para o exercício crítico da docência, para a consolidação de práticas solidarias e democráticas dentro e fora do espaço escolar, numa espécie de responsabilidade coletiva corroborando Santomé (1995).

\section{Abrangência do Programa}

Por sua natureza de programa inter-institucional, o PDE/PR envolve a Secretaria de Estado da Educação (SEED) a Secretaria de Estado de Ciência e Tecnologia (SETI), as cinco Instituições de Ensino Superior estaduais: Universidade Estadual de Londrina-UEL, Universidade Estadual de Maringá - UEM, Universidade Estadual do Centro-Oeste UNICENTRO, Universidade Estadual do Oeste do Paraná - UNIOESTE e Universidade Estadual de Ponta Grossa - UEPG e as duas instituições federais: Universidade Federal do Paraná - UFPR e Universidade Tecnológica Federal do Paraná - UTFPR.

O PDE/PR destina-se a atender 44.400 professores da rede estadual de ensino de forma indireta, por meio dos Grupos de Trabalho em Rede, e, diretamente, 1.200 professores PDE pertencentes ao Quadro Próprio do Magistério - QPM, Nível II, Classe 11, em pleno exercício de suas atividades. O objetivo é promover para o Nível III, conforme dispõe o Plano de Carreira dos Professores da Rede Pública de Ensino do Paraná na Lei Complementar n. 103, de 15 de março de 2004.

O primeiro processo de seleção ao PDE/PR ocorreu em 2006, para preencher as 1.200 vagas distribuídas em dezessete áreas curriculares. No quadro a seguir indicam as vagas proporcionalmente distribuídas de acordo com o número de professores em serviço na rede pública estadual.

Total de vagas: 1200

\begin{tabular}{|c|l|c|}
\hline 01 & Português & 200 \\
\hline 02 & Matemática & 160 \\
\hline 03 & Geografia & 80 \\
\hline 04 & História & 110 \\
\hline 05 & Ciências & 80 \\
\hline 06 & Educação Física & 90 \\
\hline 07 & Educação Artística & 40 \\
\hline 08 & Física & 30 \\
\hline 09 & Química & 30 \\
\hline 10 & Biologia & 30 \\
\hline 11 & Filosofia & 10 \\
\hline 12 & Sociologia & 10 \\
\hline 13 & Pedagogia & 130 \\
\hline 14 & Línguas Estrangeiras Modernas & 80 \\
\hline 15 & Educação e Trabalho & 20 \\
\hline 16 & Gestão Escolar & 50 \\
\hline 17 & Educação Especial & 50 \\
\hline
\end{tabular}

O Programa Curricular toma como referência as Diretrizes Curriculares da SEED e os Fundamentos Político-Pedagógicos do PDE/PR. O Professor PDE deve participar das seguintes atividades oferecidas pela universidade: Aula Inaugural, Seminários, Cursos das 
Disciplinas específicas, Elaboração e Execução do Plano de Trabalho, Coordenação de Grupos de Trabalho em Rede e Elaboração de Materiais Didáticos.

Propõe um conjunto de conteúdos constantes nas Diretrizes Curriculares para a Educação Básica, os quais deverão ser desenvolvidos no âmbito do Programa a ser executado pelas IES. O Programa Curricular está dividido em dois grandes blocos de conteúdos, constituídos da seguinte forma:

Bloco I - Fundamentos Político-Pedagógicos da SEED, cujas temáticas serão desenvolvidas pela Secretaria de Estado da Educação do Paraná por meio de Aula Inaugural e Seminário Geral.

Bloco II - Conteúdos das Áreas Curriculares Específicas, que serão desenvolvidos nos Seminários Específicos, Cursos das Disciplinas específicas e atividades pertinentes à elaboração e execução do Plano de Trabalho dos professores PDE.

\section{Fundamentos Político-Pedagógicos - SEED}

Literatura e escola - concepções e práticas. Lingüística aplicada e ensino de Língua Portuguesa.

Análise do discurso aplicada ao ensino-aprendizagem de Língua

Portuguesa.

Ensino e aprendizagem de leitura.

\section{Conteúdos específicos das áreas - IES}

Articulação entre a Educação Básica e o Ensino Superior.

Conhecimento e Teorias Pedagógicas.

A Educação e o Mundo do Trabalho.

Ciência e Cultura na contemporaneidade.

Educação a Distância e Tecnologias Educacionais

Especificamente em relação à formação dos professores nas áreas de Gestão e Pedagogia, a organização do trabalho se pautou nos seguintes conteúdos e temas: Organização do trabalho pedagógico na escola: dimensões administrativas e

Pedagógicas. Princípios da gestão escolar; Estrutura e funcionamento das instâncias colegiadas na unidade escolar; Pressupostos teóricos e práticos necessários à construção coletiva do Projeto Político-Pedagógico da escola pública. A relação entre as diversas concepções de educação, sociedade, escola e ser humano na sociedade atual.

$\mathrm{Na}$ área de Pedagogia: O projeto político-pedagógico como expressão da política pedagógica da escola e do trabalho coletivo. A construção do Projeto Político-Pedagógico da escola; As relações entre trabalho e educação; Elementos da prática pedagógica; A organização da escola e instâncias de decisão colegiada; Os elementos da cultura escolar: saberes escolares, método didático, avaliação escolar e relações coletivas do trabalho docente; O papel dos pais e da escola na educação; Autonomia da escola pública; Paradigma - relação de poder - Projeto Político-Pedagógico: dimensões indissociáveis do fazer educativo.

O papel do professor e do pedagogo na concretização do currículo escolar; Elementos constitutivos das ações do pedagogo na organização do trabalho pedagógico na escola pública; Aspectos históricos e políticos da formação do professor e do pedagogo no Brasil e sua prática escolar.

Fundamentos políticos e política educacional: Políticas educacionais brasileiras contemporâneas e legislação correspondente; $\mathrm{O}$ atual sistema educacional brasileiro: níveis 
e modalidades de ensino; A lei 9394/96 face às necessidades históricas da educação brasileira; As Diretrizes Curriculares para a educação básica.

O contexto histórico-político do Estado brasileiro as políticas educacionais nacionais e estaduais. Educação Básica: organização, gestão e financiamento. Administração Escolar: aspectos históricos e conceituais. Gestão democrática da educação: fundamentos e princípios. Gestão democrática da escola pública: dimensão pedagógica, administrativa e legal.

Conteúdos específicos das áreas - IES Metodologia da pesquisa educacional. Gestão do sistema público de educação: Plano Estadual de Educação e Lei de Sistema. Avaliação Institucional. Legislação Educacional. Articulação entre a Educação Básica e o Ensino Superior. Conhecimento e Teorias Pedagógicas. A Educação e o Mundo do Trabalho.

Ciência e Cultura na contemporaneidade. Educação a Distância e Tecnologias Educacionais.

Sobre a metodologia do programa, o PDE/PR foi estruturado por meio de um plano de trabalho, no qual incluem seminários, encontros com os professores/as, atividades de formação nas IES e integração por rede. As incumbências dos/as Professores/as PDE são: a elaboração do plano de trabalho em concordância com o/a orientador/a nas IES, a participação nos estudos com o grupo de colaboração em rede, onde o Professor PDE posta os textos e encaminham possíveis reflexões e debates junto aos pares nas escolas. E ainda, elaboração de material didático condizente com o objeto de estudo definido no plano de estudos. Esse material é denominado caderno didático, que após a impressão, fica a disposição das escolas estaduais para uso e discussão. Atualmente está disponível no site www.diadiaeducacao.pr.gov.br o primeiro caderno temático elaborado pelos/as professores e professoras conjuntamente aos seus/as orientadores/as.

Segundo as diretrizes do Programa, o PDE/PR estimula, igualmente, a produção de diferentes formas de materiais didáticos. Por exemplo, a produção de roteiros e os programas para televisão paranaense (TV Educativa e TV Paulo Freire), o vídeo-aula ou documentário para inserção na TV Paulo Freire e materiais impressos em forma de livros e mapas para serem utilizados dentro ou fora das salas de aula, entre outras. São válidas também produções conjuntas relacionadas aos Projetos Educação Com Ciência, Festival de Arte da Rede Estudantil - Fera e Jogos Colegiais.

Uma proposta do programa contempla também a Orientação de Grupos de Trabalho em Rede. Essa atividade configura-se como estratégia de democratização do conhecimento. É por meio dela que o Professor PDE socializa os conhecimentos apreendidos, desde o início do Programa, para os demais professores da rede pública estadual, considerando as suas áreas curriculares específicas de atuação.

Dessa forma, cada Professor em processo de formação desempenha a função de Orientador de Grupo de Trabalho em Rede, com previsão de atendimento de no máximo, 37 (trinta e sete), professores/as da Rede. Essa atividade é realizada de forma semipresencial. A carga horária presencial é realizada nos estabelecimentos de ensino da rede pública estadual e a carga horária de formação a distância é realizada com o apoio do Sistema SACIR ${ }^{6}$.

Todo este esforço na participação do programa culmina com a elaboração de um artigo cientifico que após ser avaliado pelo/a professor/a orientador/a da IES é encaminhado aos Núcleos Regionais de Ensino (NRE) para posteriormente ser publicado em revistas científicas. 


\section{Uma avaliação possível:}

Todo programa deve ser avaliado, entretanto no caso do PDE/PR, entendemos que ainda é incipiente emitir uma avaliação. Por isso, realizamos apenas uma primeira aproximação avaliativa. Em linhas gerais, a avaliação é considerada uma etapa de finalização do processo de ensino e aprendizagem. A concepção de avaliação recomendada no documento oficial do PDE/PR, explica que se deve adotar um processo contínuo, sistemático e progressivo das atividades desenvolvidas pelos/as professores/as participantes, seja em sua forma coletiva ou individual. Isso corresponde a uma concepção diagnóstica de avaliação.

Nessa perspectiva, os princípios pedagógicos apontados pelo Programa precisam encontrar ressonância direta nos processos avaliativos dos professores participantes do PDE/PR. A avaliação dos planos de trabalho e o desenvolvimento das atividades, culminando com sua certificação. Por outro lado, a avaliação institucional do Programa será permanente com a integração de atividades de Coordenação já consideradas durante o processo de institucionalização do Programa entre SEED, SETI e as IES.

A avaliação inicial desse programa inédito no Estado do Paraná é aparentemente promissora. No ano de 2007, quando efetivamente foi iniciado, foram selecionados os projetos pedagógicos para que os/as professores/as PDE pudessem efetivamente dedicar-se à sua formação recebendo o salário durante o período de afastamento. Essa formação é realizada nas universidades públicas do Estado que disponibilizam docentes, funcionários e a estrutura física onde se realizam cursos, eventos e orientações individuais ao/à Professor/a PDE. Apesar de o governo ter aberto concurso para ampliar o quadro de docentes nas IES públicas paranaenses, por conta do programa, a demanda de professores/a PDE tem aumentando consideravelmente o fluxo de trabalho dos orientadores isso significa que ainda é insuficiente o número de professores disponíveis para a viabilidade dessa modalidade de formação.

Os professores e as professoras participantes da primeira edição do programa 20072008 que culminaram seus estudos no ano de 2009, ao retornarem às suas escolas de origem tem manifestado entusiasmo ao desenvolver as atividades propostas, tanto pelas IES quanto em seus planos de ação junto às escolas. Suas práticas iniciais uma vez instrumentalizadas passam a ter um novo sentido, podendo gerar uma nova práxis. Esse entusiasmo denotado entre os participantes do PDE/PR articulou novas ações para a edição 2008-2009.

Nesta investigação, delimitamos o período de abrangência dos anos iniciais do programa entre 2007 a 2009. Os/as professores/as PDE, em 2007, foram acompanhados e orientados para produzirem um material didático pedagógico, pertinente ao seu objeto de estudo que foi sistematizado no projeto de intervenção pedagógica na escola, de acordo com a sua área ou disciplina de ingresso no Programa. Por exemplo, um/a professor/as que se inscreveu para participar da área de gestão escolar, terá a responsabilidade de materializar o projeto na área de gestão junto à comunidade escolar ao retornar à sua escola de origem, conforme a área de formação no PDE/PR.

A coordenação Estadual do PDE/PR indica para a produção de Projeto Folhas, uma metodologia de material didático-pedagógica, especialmente, para alunos/as da educação básica e a elaboração de um Objeto de Aprendizagem Colaborativa (OAC). O PDE/PR estimula ainda a realização de outras produções didático-pedagógicas, desde que mantenham relação com as ações já em curso no âmbito das diretrizes da SEED, tais como: vídeos com aulas, produção de roteiros e programas para televisão, documentários para a TV Paulo Freire ou TV Educativa (emissora de TV do governo estadual, vinculada a SEED) e ainda, materiais impressos, livros e mapas para a utilização no espaço escolar. 
No terceiro período do Programa, o/a professor/a PDE põe em prática o seu projeto na escola. Está atividade compreende ações planejadas e desenvolvidas ao longo do processo de orientação junto às IES paranaenses, participando de cursos, eventos e outras produções, desenvolvidas no primeiro ano do programa. No terceiro e quarto períodos, os/as professores/as PDE coordenarão em sua escola de lotação um grupo de estudo, a fim de contribuir para a implementação do seu projeto na escola. Esta atividade objetiva integrar os pares às reflexões já realizadas pelos professores PDE, durante o primeiro ano do programa, tendo certificação pela SEED com carga horária de 30 horas, o que contribui para o avanço na carreira dos/as demais professores/as.

O objetivo dessa modalidade de formação continuada em serviço é proporcionar aos/às professores/as da rede pública estadual subsídio teórico e prático para o desenvolvimento de ações educacionais sistematizadas, que possam ser avaliadas em seu processo e em seu produto e que resultem em redimensionamento de sua prática educativa. Estimular a pesquisa sobre a sua prática docente, produzir materiais para serem utilizados nas escolas pelos seus pares e participar de eventos científicos submetendo seus textos a avaliação.

Como nos lembra Paulo Freire, educação não é sinônimo de transferência de conhecimento pela simples razão de que não existe um saber pronto e acabado. O saber não é uma simples cópia ou descrição da realidade empírica e estática. A realidade precisa ser decifrada e reinventada a cada momento, por ser extremamente dinâmica.

O objeto de toda e qualquer pesquisa na educação é a permanente busca de conhecimento centrado na descoberta, análise e transformação da realidade pelos que a vivem. "Quanto mais investigo o pensar do povo com ele, tanto mais nos educamos juntos. Quanto mais nos educamos, tanto mais continuamos investigando. Educação e investigação se tornam momentos de um mesmo processo" (FREIRE, 2007, p. 20).

Vieira Pinto (1969) aponta quatro aspectos que em sua opinião merecem atenção pela repercussão que tem como compreensão do papel da prática na condução da pesquisa científica. Primeiro, o autor se refere à intencionalidade da prática como critério de verdade; segundo, refere-se à sua natureza sempre social; terceiro, à necessidade da ação conjunta na pesquisa cientifica; e, quarto, à sua realização efetiva na qualidade de trabalho humano (p. 229).

A prática, segundo ele, é movida por uma finalidade, àquela que a operação sobre a natureza ou o exame de um fato social, destinado a negar ou confirmar uma proposição, corresponde a um fim que o homem tem em vista, em razão do seu engajamento no processo produtivo. $\mathrm{O}$ fundamento da prática encontra-se na necessidade de inclusão do homem no processo em que produz o que precisa ao mesmo tempo em que produz a si mesmo, pelo acúmulo de conhecimentos que adquire. A experiência científica é concebida em função das experiências do homem.

A prática enquanto confirmação do conteúdo da idéia imaginada resulta de uma finalidade existencial, determinada pelo engajamento racional do homem no processo da natureza, especialmente no processo econômico-produtivo; a prática dá origem a novas finalidades para o ser humano, pois engendra novas idéias, que farão o homem ver e conhecer o mundo de maneira mais extensa, aprofundada e exata.

$\mathrm{Na}$ prática dos/as professores/as, o programa tende a garantir uma formação contextualizada, engendrada no cotidiano escolar. Da forma como está instituído, contribui para transformar a escola em um espaço para troca de expectativas, experiências e vivências. É uma oportunidade de potencializar esforços e possibilidades de enfrentamento das 
contradições e desafios que marcam o trabalho docente, especialmente em uma época de supervalorização da técnica, em detrimento do conhecimento humano.

A experiência do Professor PDE, bem como de professores/as das IES, representa a possibilidade real de articulação da Educação Básica com a Educação Superior, na busca por alternativas de mudanças para o ensino público. A formação continuada contribui para estabelecer o dialogo entre os pares, e isso atualmente é uma necessidade premente dos/as educadores/as diante da complexidade tecnológica que adentra o espaço escolar.

A formação dos professores e das professoras devia insistir na constituição
deste saber necessário e que me faz certo desta coisa óbvia, que é a
importância inegável que tem sobre nós o contorno ecológico, social e
econômico em que vivemos. E ao saber teórico desta influência teríamos que
juntar o saber teórico-prático da realidade concreta em que os professores
trabalham (FREIRE, 2007, p.137).

Freire argumenta que, quando o professor e a professora se encontram inseridos em um processo de formação para ele, isso deve ser permanente, a reflexão crítica sobre a prática se torna uma exigência da relação teoria/prática:

[...] é preciso que, desde o começo do processo, vá ficando cada vez mais claro, que embora diferentes entre si, quem forma se forma e re-forma ao formar e quem é formado forma-se e forma ao ser formado. É neste sentido que ensinar não é transferir conhecimentos, conteúdos, nem formar é ação pela qual o sujeito criador dá forma, estilo ou alma a um corpo indeciso e acomodado. Não há docência sem discência, as duas se explicam e seus sujeitos apesar das diferenças que os conotam, não se reduzem à condição de objeto, um do outro. Quem ensina aprende ao ensinar e quem aprende ensina ao aprender (FREIRE, 2007, p.23).

Ao estabelecer essa ligação entre o formador e o formado, Freire trata da autenticidade exigida pela prática de ensinar e aprender, "ensinar inexiste sem aprender e vice-versa e foi aprendendo socialmente que, historicamente homens e mulheres descobriram que era possível ensinar" (Freire, 2007, p.24-25). Para o autor, esse processo pode deflagrar no aprendiz uma curiosidade crescente, que pode com isso torná-lo mais criador, o que ele chama de curiosidade epistemológica. Para Snyders (1988) em se tratando da formação dos professores:

[...] a primeira reforma da formação de professores seria para mim que eles atingissem um entusiasmo cultural, a confiança de que a cultura que eles ensinam pode dar satisfação a seus alunos; num certo sentido, ela está destinada a dar satisfação; ensina-se para dar satisfação; ao mesmo tempo em que se estuda matemática, alunos e professores juntos devem se questionar, sobre a satisfação que se pode ter ao fazê-lo. Ser professor é ter se aproximado dos grandes sucessos - e estar a seu serviço, querer comunicar à alegria que daí decorre exortar os alunos a reclamar da escola essa satisfação que lhes é devida pela escola (SNYDERS, 1988. p.14).

O PDE/PR parece estabelecer institucionalmente essa interlocução entre formador e formado, entre universidade e escola pública. Seu êxito será o resultado de um trabalho pedagógico desenvolvido, por professores e professoras estimulados, que defendem a relevância da escola pública como local de trabalho e compreendem sua função na sociedade. 
Nos limites deste artigo, apresentamos o PDE/PR como uma política de formação continuada e de valorização da carreira docente na rede pública estadual, articulando as IES públicas para fortalecer essa instância universitária de formação docente. Em se tratando do conjunto de medidas que configuram a atual política governamental paranaense, é importante reiterar que o contexto prioritário de aplicação dessas medidas tem sido a formação dos/as professores/as. Essa garantia de prioridade está devidamente institucionalizada como política de Estado pelos próximos dez anos.

O Plano Nacional de Desenvolvimento da Educação é abrangente e contêm inúmeras ações de governo, no entanto, em se tratando de ações relevantes, no seu conjunto são ações performáticas. Ao acessarmos o site do MEC, especificamente na página do PDE, temos contato com um emaranhado de ações e programas que impressionam, até mesmo pelo impacto visual e pela performance tecnológica, apresentando-se como soluções para todos os problemas da educação. Contudo, um olhar mais acurado revela que em sua maioria as ações propostas são para atender as evidências do IDEB (Índice de desenvolvimento da Educação Básica) e impor um currículo pensado desde fora.

O Estado neoliberal, nesses últimos vinte anos, desmantelou o sistema público de ensino, contribuindo para o desmantelamento da educação pública seja ela Básica ou Superior. O efeito de uma nova política pública no Paraná pode ir além das práticas fragmentadas de formação docente. O PDE/PR parece ensejar uma tentativa de superação das práticas desastrosas e conservadoras na busca de práticas emancipatórias, o pano de fundo desse programa é a melhoria na qualidade do ensino nas escolas públicas.

Nessa breve avaliação destacamos a pertinência de evidenciar a proposta dessa modalidade de formação como um avanço teórico-prático. O que consideramos relevante nessa proposta é a possibilidade de os/as professores/as se afastarem integralmente das atividades em suas escolas para se dedicar exclusivamente à sua formação, com tempo e espaço reservado para esse fim. Assim observa-se que os/as professores/as PDE tiveram a oportunidade de receber uma formação continuada de qualidade, dedicando-se integralmente aos estudos, o que no exercício cotidiano do trabalho docente não é possível. Isso incluiu um redimensionamento por parte do governo estadual mais especificamente da Secretaria de Estado da Educação, bem como da Secretaria de Estado da Ciência e Tecnologia e Ensino Superior, pois ambas necessitaram rever o quadro de pessoal, ampliando-o para atender a demanda ampla de professores/as em formação.

Dimensionar o alcance desse programa, não é tarefa fácil, entendemos que essa modalidade de formação representa um avanço coerente na educação pública. A luta pela qualidade de ensino é corroborada por uma formação crítica de seus professores/as. O PDE/PR na atual conjuntura se configura como lei estadual, garantido por uma década. Isso denota que independentemente dos governantes, esse processo formativo terá sua continuidade garantida, e isso pode favorecer o fortalecimento do corpo docente das escolas.

O PDE/PR atualmente continua sendo analisado e discutido pela APP Sindicato junto aos gestores do Estado cuja defesa é sobre a oferta dessa modalidade de formação extensiva a todos os docentes estaduais em exercício, não somente aos/às professores/as que se encontram no último nível de progressão na carreira como prescreve a legislação. $\mathrm{Na}$ atual configuração do programa os/as professores/as em início de carreira terão que esperar de doze a quinze anos para participar do PDE/PR. Esse provavelmente seja um dos limites dessa formação. Isso denota que mais uma vez, apesar de ser uma prática inovadora, o Estado articulado à racionalidade, freia o acesso dos professores/as iniciantes e oferta essa formação somente para os que estão ao final de carreira, conseqüentemente, posterga a progressão profissional e o aumento de salários. 
Corroboramos Saviani (2009) quando expressa que:

[...] é preciso lembrar ao Estado de que a formação de professores é, e deve ser cada vez mais, atribuição da educação superior. E, sem professores bem formados, as metas da educação básica não poderão ser atingidas. Portanto, sem uma forte ampliação do financiamento público ao ensino superior, a busca de melhoria da qualidade da educação básica terá dificuldades de chegar a resultados significativos (SAVIANI, 2009, p.45).

Como formadoras de professores e professoras, entendemos ser necessário e urgente à articulação de práticas fortalecedoras às práticas inovadoras existentes para que não sejam efêmeras e tenham uma duração que possibilitam a esperança na mudança, bem como possam servir de referência a quem está querendo mudar.

\section{Considerações}

A pertinência da organização do PDE/PR como um programa de formação para os professores e professoras em exercício da profissão, está na consolidação de uma formação junto as IES. O trabalho coletivo de professores/as na produção acadêmica disponibilizado no Portal dia-a-dia educação já traz alguns resultados positivos e reflexões acerca dos conteúdos contemplados no currículo oficial da educação básica. Entretanto, ainda é incipiente tecer um diagnóstico mais preciso sobre os resultados alcançados até o momento.

Em nossa concepção de educação entendemos que a formação de professores e professoras deve abrir um campo de possibilidades criativas e inventivas para novas reflexões pedagógicas. Defendemos a criação de novas práticas para descobrir alternativas que superem os equívocos e busquem as opções na direção emancipatória.

O Programa de Desenvolvimento Educacional - PDE apresenta uma possibilidade para a formação de professores da rede pública do Estado do Paraná e entre suas propostas pedagógicas oferece subsídios para pensar a discussão de um tema relevante ao cenário educacional brasileiro: a necessidade da criação de um sistema integrador entre as escolas de Educação Básica e as Instituições de Ensino Superior. Para que isso se efetive é necessário o trabalho coletivo entre as instâncias formativas ensejando e lutando pela materialidade de novas políticas e práticas que contemplem uma educação de qualidade, cujo objetivo não esteja relacionado apenas à classificação estatística das crianças e das escolas. A criação, implantação e divulgação de possíveis programas de formação de professores e professoras é uma possibilidade ímpar de aliar a universidade e a escola básica para além das práticas de tergiversação.

\section{Referências:}

BARRETO, Raquel Goulart. As tecnologias na política nacional de formação de professores a distância: entre a expansão e a redução. In. Educação \& Sociedade. Vol.29 - Número especial. São Paulo: Cortez; Campinas Cedes, 2008. p. 919-937.

BRASIL. Lei de Diretrizes e Bases da Educação Nacional: lei n. 9394/96. Brasília: MEC, 1996.

DOURADO, Luiz Fernandes. Políticas e gestão da educação superior à distância: novos marcos regulatórios? In. Educação \& Sociedade. Vol.29 - Número especial. São Paulo: 
Cortez; Campinas Cedes, 2008. Pág.891-917.

FREIRE, Paulo. Pedagogia da Autonomia: Saberes necessários à prática educativa. São Paulo : Paz e Terra, 2007.

NEGRÃO, Sonia Maria Viera. Atuação e Formação de Professores: primeiras lições do tempo. In. ALTOÉ, A. Temas de Educação Contemporânea. Cascavel : Edunioeste, 2008. p.179-198.

PARANÁ. Secretaria de Estado da Educação. Avaliação, sociedade e escola: fundamentos para a reflexão. 2. ed. Curitiba: SEED, 1986.

PINTO, Álvaro Vieira. Ciência e Existência - problemas filosóficos da pesquisa científica. Rio de Janeiro, Paz e Terra. 1969.

RODRIGUES, Neidson. Da Mistificação da Escola a Escola Necessária. São Paulo: Cortez, 2000 .

SANTOMÉ, Jurjo Torres. As Culturas Negadas e Silenciadas no Currículo. In. Silva, Tomaz Tadeu (Org.). Alienígenas na Sala de Aula. Uma introdução aos estudos culturais em educação. Petrópolis, RJ : Vozes, 1995. p.159-177.

SAVIANI, Dermeval. PDE - Plano de Desenvolvimento da Educação: Análise crítica da política do MEC. Campinas, SP : Autores Associados, 2009.

SNYDERS, Georges. A Alegria na Escola. Trad. Bertha Halpern Guzovitz, Maria Cristina Caponero. São Paulo: Manole Ltda, 1988.

TERUYA, Teresa Kazuko. Trabalho e Educação na Era Midiática. Um estudo sobre o mundo do trabalho na era da mídia e seus reflexos na educação. Maringá, PR: Eduem, 2006.

Notas:

\footnotetext{
${ }^{1}$ Versão revisada e ampliada do trabalho apresentado na IX JORNADA DO HISTEDBR: "O nacional e o local na História da Educação", realizado no período de 07 a 09 de julho de 2010, na Universidade Federal do Pará (UFPA) em Belém, PA.

${ }^{2}$ Professora do Centro de Educação e Letras da Universidade Estadual do Oeste do Paraná - CEL - UNIOESTE Foz do Iguaçu -PR. Doutoranda em Educação pela Universidade Estadual de Maringá - UEM-PR, email: denisepedagoga@gmail.com

${ }^{3}$ Mestranda em Educação pela Universidade Estadual de Maringá-UEM/PR. Graduada em Publicidade e Propaganda pela Universidade Estadual do Oeste do Paraná - UNIOESTE de Guarapuava - PR , email: lalexgomes@gmail.com

${ }^{4}$ Professora Associado do Departamento de Teoria e Prática da Educação - DTP e do Programa de PósGraduação em Educação - PPE (Mestrado e Doutorado) da Universidade Estadual de Maringá-UEM/PR. Pesquisadora Colaboradora da Faculdade de Educação da Universidade de Brasília - FE/UnB/DF (2008-2010). Líder do Grupo de Estudos e Pesquisas em Psicopedagogia, Aprendizagem e Cultura - GEPAC da UEM, homepage: www.nt5.net.br - email: $\underline{\text { tkteruya @uem.br }}$
} 
${ }^{5}$ O Programa de Desenvolvimento Educacional - PDE implantado no estado do Paraná está disponibilizado pela Secretaria de Estado da Educação do Paraná no Portal dia-a-dia Educação, um sistema próprio que proporciona a integração e a articulação entre os sujeitos e as instituições.

${ }^{6}$ O Sistema de Acompanhamento e Integração em Rede - SACIR é um sistema informatizado que foi construído em um Ambiente Pedagógico Colaborativo (APC). O APC é um sistema já utilizado na rede pública estadual para a elaboração e disseminação de conteúdos curriculares pelos/as professores/as.

Recebido em: $\quad$ 19/01/11

Aprovado em: $17 / 03 / 11$ 